See Article page 1689.

\section{Commentary: Enhanced recovery-It's about more than just the length of stay}

\author{
Erin M. Corsini, MD, and Mara B. Antonoff, MD
}

In this issue of the Journal, Razi and colleagues ${ }^{1}$ describe their experience with their institutional enhanced recovery after thoracic surgery (ERATS) protocol and its effects on pain scores and opioid use in a thoracic surgical population. Although some aspects of the study are underpowered and may be lacking novelty relative to previous investigations, a very valuable aspect of the study relates to the investigators' analysis of opioid prescription filling. ${ }^{2}$ They have taken advantage of the state of Florida's electronic system for tracking controlled substances to evaluate interesting outcomes pertaining to the filling of prescriptions, data that have not been well described heretofore. The report of Razi and colleagues ${ }^{1}$ is timely and well-executed, and it serves as an exemplary reminder of the power of ERATS pathways as a component of our care. Although the extent to which the opioid prescribing patterns of Razi and colleagues ${ }^{1}$ can be generalized to other centers is not certain, their report is nonetheless valuable, highlighting as it does the association between a deliberate ERATS program and a reduction in opioid use, most notably in the postdischarge period. This metric is meaningful on the individual, institutional, and global scales.

Skeptics would have us believe that the advent and rise of ERATS pathways have been largely driven by cost—standardized programs aimed at reducing hospital length of stay. It is important, however, for the thoracic surgical community to appreciate all aspects of patient care that are improved with such programs. Although it is true that ERATS protocols appear to be beneficial in reducing hospital length of stay and cost, ${ }^{3}$ patients also have significantly

From the Department of Thoracic and Cardiovascular Surgery, the University of Texas MD Anderson Cancer Center, Houston, Tex.

No funding was provided for this article.

Disclosures: Authors have nothing to disclose with regard to commercial support.

Received for publication Jan 2, 2020; accepted for publication Jan 2, 2020; available ahead of print Jan 25, 2020.

Address for reprints: Mara B. Antonoff, MD, Department of Thoracic and Cardiovascular Surgery, University of Texas MD Anderson Cancer Center, 1515 Holcombe Blvd, Houston, TX 77030 (E-mail: MBAntonoff@mdanderson.org).

J Thorac Cardiovasc Surg 2021;161:1702-3

$0022-5223 / \$ 36.00$

Copyright (c) 2020 by The American Association for Thoracic Surgery

https://doi.org/10.1016/j.jtcvs.2020.01.018

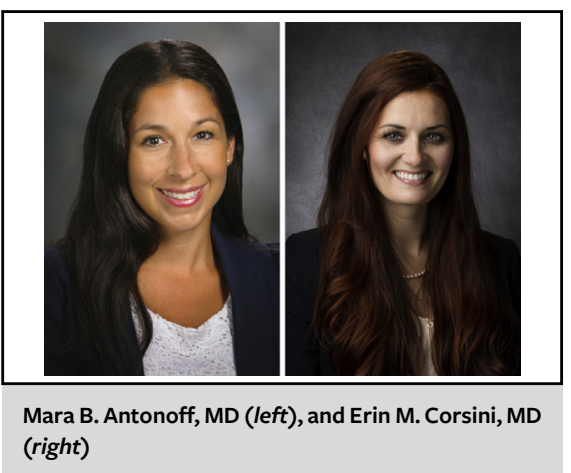

CENTRAL MESSAGE

Razi and colleagues demonstrate

significant reduction in opioid

use with enhanced recovery

pathway implementation, further

strengthening the impetus for

our community to embrace such

protocols.

fewer complications , $^{2,3}$ and successfully complete adjuvant therapy sooner and at increased rates. ${ }^{4}$ Importantly, as we consider a reduction in perioperative morbidity, we also must think differently about anticipating and managing such complciations ${ }^{5}$, as many may occur outside of the hospital, in part as a result of decreased length of stay; this is analogous to Razi and colleagues' report ${ }^{1}$ of the effects of ERATS pathways observed even after discharge, with decreased opioid use at home. We must consider that such programs affect patients not only during their hospitalizations but for some time thereafter, and prescribing practices should be adapted accordingly.

Ultimately, Razi and colleagues ${ }^{1}$ present a relevant article with significant findings of dramatically decreased postdischarge opioid use. With a worrisome opioid epidemic upon us, we should appreciate this report and applaud Razi and colleagues ${ }^{1}$ for their commitment to their institutional ERATS program and, in turn, their patients. Thanks to studies such as this, we can easily recognize that ERATS is not just a means of reducing costs and discharging patients sooner; these programs are valuable to our field, with considerable public health implications.

\footnotetext{
References

1. Razi SS, Stephens-McDonnough JA, Haq S, Fabbro M II, Sanchez AN, Epstein RH, et al. Significant reduction of postoperative pain and opioid analgesics requirement with an enhanced recovery after thoracic surgery protocol. $J$ Thorac Cardiovasc Surg. 2021;161:1689-701.
} 
2. Van Haren RM, Mehran RJ, Mena GE, Correa AM, Antonoff MB, Baker CM, et al. Enhanced recovery decreases pulmonary and cardiac complications after thoracotomy for lung cancer. Ann Thorac Surg. 2018;106:272-9.

3. Haro GJ, Sheu B, Marcus SG, Sarin A, Campbell L, Jablons DM, et al. Perioperative lung resection outcomes after implementation of a multidisciplinary, evidence-based thoracic ERAS program. Ann Surg. December 5, 2019 [Epub ahead of print].
4. Nelson DB, Mehran RJ, Mitchell KG, Correa AM, Sepesi B, Antonoff MB, et al Enhanced recovery after thoracic surgery is associated with improved adjuvant chemotherapy completion for non-small cell lung cancer. J Thorac Cardiovasc Surg. 2019;158:279-86.e1.

5. Antonoff MB. Commentary: predicting patients at risk for complications after thoracic surgery-application in the era of enhanced recovery. J Thorac Cardiovasc Surg. 2019;157:2502-3.
See Article page 1689.

\section{Commentary: Enhanced recovery and postoperative opioid use: Good for the patient, good for society?}

\author{
Timothy J. P. Batchelor, BSc, MBChB, MSc, FRCS \\ (CTh)
}

Some elements of patient care, including opioid use for acute pain management, are associated with delayed recovery from surgery. ${ }^{1}$ Furthermore, prescription opioids are implicated in the so-called opioid epidemic experienced most keenly in North America ${ }^{2}$ but now also seen increasingly elsewhere. ${ }^{3}$ Although the causes of the opioid crisis are complex, changes in perioperative prescribing practices with newer formulations of synthetic opioid analgesics are partly to blame. Approximately 5\% of patients prescribed opioids will go on to become dependent on them. ${ }^{4}$

Enhanced recovery after surgery (ERAS) describes a multifaceted approach to perioperative care that aims to reduce the body's deleterious stress response to surgery and thus accelerate recovery. A key component is an opioid-sparing approach to pain relief. Recommendations after lung cancer surgery include patient education, regional anesthesia (preferably without thoracic epidural), acetaminophen in combination with nonsteroidal antiinflammatory drugs, glucocorticoids, and ketamine. ${ }^{5}$ Other potential adjuncts, such as liposomal bupivacaine and the

\footnotetext{
From the Department of Thoracic Surgery, University Hospitals Bristol NHS Foundation Trust, Bristol Royal Infirmary, Bristol, United Kingdom.

Disclosures: Dr Batchelor reports honoraria from Medtronic and Johnson \& Johnson, and consultancy fees from AstraZeneca.

Received for publication Jan 12, 2020; accepted for publication Jan 14, 2020; available ahead of print Jan 25, 2020.

Address for reprints: Timothy J. P. Batchelor, BSc, MBChB, MSc, FRCS (CTh), Department of Thoracic Surgery, University Hospitals Bristol NHS Foundation Trust, Bristol Royal Infirmary, Bristol BS2 8HW, United Kingdom (E-mail: tim. batchelor@uhbristol.nhs.uk).

J Thorac Cardiovasc Surg 2021;161:1703-4

$0022-5223 / \$ 36.00$

Copyright (C) 2020 by The American Association for Thoracic Surgery

https://doi.org/10.1016/j.jtcvs.2020.01.020
}

\section{Check for updates}

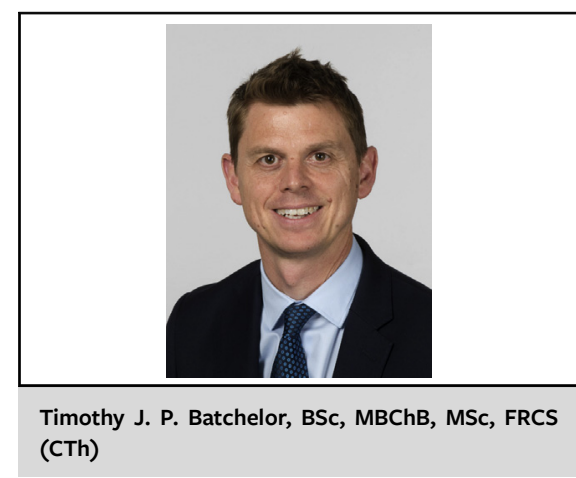

CENTRAL MESSAGE

Enhanced recovery programs

reduce opioid consumption

postoperatively and after

discharge with potential benefi-

cial effects for both the individual

patient and the opioid epidemic.

prophylactic use of gabapentinoids, show promise and are subject to ongoing studies.

In this issue of the Journal, Razi and colleagues ${ }^{6}$ describe the successful implementation of an ERAS program after thoracic surgery. Their goal was to unify patient care by consolidating perioperative care elements into one ERAS protocol, thereby streamlining the patient pathway and reducing variability in outcomes. They achieved reductions in in-hospital postoperative pain scores for both open and robotic lung resections. At the same time, they observed a reduction in in-hospital opioid use for robotic surgery but not open surgery (although this may be due to the laudable elimination of thoracic epidurals in the open group). Perhaps the most important outcome, however, was the striking reduction in postdischarge opioid use, most marked in the open group of patients. This information was available to the authors because Florida has a statewide 